\title{
Aspectos físicos químicos e microbiológicos da urina de matrizes suínas descartadas
}

\author{
Physical - chemical and microbiologic aspects from the urine of \\ culled sows
}

\section{Regiani Nascimento Gagno Pôrto ${ }^{1}$ Jurij Sobestiansky² ${ }^{2}$ Moema Pacheco Chediak Matos ${ }^{3}$ Maria Lúcia Gambarini ${ }^{4}$}

\section{RESUMO}

\begin{abstract}
O presente estudo objetivou descrever as alterações físico-químicas da urina, identificando os agentes etiológicos presentes na urina de matrizes descartadas sem causa definida. De 35 amostras examinadas, 16 (45,7\%) foram positivas para presença de sangue elou nitrito (positivo para infecção urinária, IU); 8 (50\%) tiveram coloração amarela escura e $6(37,5 \%)$ coloração amarela clara; $2(12,5 \%)$ amostras não apresentavam alteração. Dez amostras tinham odor amoniacal, das quais 7 foram positivas para IU. Também houve prevalência de urinas turvas e turvas com grumos, bem como de pH normal (5,5 - 6,5) e densidades maiores que 1,012. Presença de microrganismos foi verificada em 91,5\% das 35 amostras examinadas, sendo a Escherichia coli (45,7\%), a bactéria com maior prevalência. Em 11 amostras (31,4\%), verificou-se a presença de Actinobaculum suis; destas, 4 foram simultaneamente positivas para $I U$ e Actinobaculum suis; 7 foram negativas para IU, observandose porém, a presença de Actinobaculum suis pelo exame de imunofluorescência indireta.
\end{abstract}

Palavras - chave: Matrizes suínas, infecção urinária, Actinobaculum suis, aspecto físico químico da urina.

\section{ABSTRACT}

The present study describes the physical-chemical alterations of the urine and identifies etiological agents of the urine of 35 sows. Out of 35 samples, 16 (45.7\%) were positive for nitrite and/or blood, positive for urinary infection (UI); eight (50\%) were dark yellow and six (37.5\%) had clear yellow coloration; in two (12.5\%) samples did not show any alteration. Ten samples had ammonia smell, seven among them were positive for UI. Other findings were turbid urine and turbid with grumes, normal $\mathrm{pH}$ values $(5.5-6.5)$ and densities higher than 1012. Microorganisms were isolated in $91.5 \%$ out of 35 urine samples, with prevalence of Escherichia coli (45.7\%). In 11 samples (31.4\%) Actinobaculum suis was isolated, four were simultaneously positive for UI and Actinobaculum suis; seven were negative for UI, but it was observed the presence of Actinobaculum suis in the indirect immunofluorescence.

Key words: sows, urinary infection, Actinobaculum suis, physical-chemical aspects of urine.

\section{INTRODUÇÃO}

Nas últimas décadas, as patologias do sistema urinário não foram assunto prioritário, provavelmente por sua baixa ocorrência. Porém, a intensificação e confinamento da criação de suínos evidenciou, em muitas granjas, problemas de produtividade relacionados à alta incidência de infecções urinárias, motivando estudos principalmente no que diz respeito aos agentes etiológicos, suas

\footnotetext{
${ }^{1}$ Médico Veterinário, Professor Assistente, Mestre, Departamento de Medicina Veterinária, Escola de Veterinária (EV), Universidade Federal de Goiás (UFG), Campus II. CP 131, 74001-970, Goiânia, Go. E-mail: rngporto@vet.ufg.br

${ }^{2}$ Médico Veterinário, Professor Titular, Doutor, Departamento de Medicina Veterinária, EV, UFG.

${ }^{3}$ Médico Veterinário, Professor Assistente, Departamento de Medicina Veterinária, EV, UFG.

${ }^{4}$ Médico Veterinário, Professor Adjunto, Doutor, Departamento de Produção Animal, EV, UFG.
} 
características e a relação entre hospedeiro, agente etiológico e fatores ambientais no desencadeamento da doença (SOBESTIANSKY et al., 1995).

A infecção urinária na fêmea suína está entre as principais causas de falhas reprodutivas que influem na produtividade do rebanho por afetarem, principalmente, a saúde geral das matrizes e aumentarem consideravelmente a taxa de reposição sendo ela considerada a doença endêmica mais importante da fêmea suína em produção (MADEC, 1984; REIS et al., 1992). As perdas caracterizam-se por problemas reprodutivos, como redução do tamanho da leitegada, aumento nas taxas de retorno ao cio, aborto, síndrome mastite-metrite-agalaxia e de anestro (SOBESTIANSKY \& WENDT, 1993). Neste contexto, PETERSEN (1980) estimou as perdas econômicas por porcas que apresentavam infecção urinária antes e após o parto em US\$160,00.

Em geral, entre os microorganismos encontrados com maior freqüência nas infecções urinárias estão as bactérias Escherichia coli, Staphylococcus spp., Streptococcus spp. e o Actinobaculum suis (SOBESTIANSKY \& WENDT, 1993). Desta forma, o presente trabalho teve por objetivos, investigar e caracterizar as alterações físicoquímicas e identificar os agentes etiológicos presentes na urina de fêmeas suínas descartadas sem causa definida.

\section{MATERIALEMÉTODOS}

O presente estudo foi realizado em 35 fêmeas suínas descartadas sem causa definida, provenientes de cinco granjas, com, em média, 45 matrizes em produção, localizadas num raio de $200 \mathrm{~km}$, tendo Goiânia - Go como ponto central. As colheitas de urina foram realizadas nas granjas ou nos matadouros, segundo metodologia descrita por ALBERTON et al. (1996).

No Laboratório de Bacteriologia do Departamento de Medicina Veterinária da Escola de Veterinária da Universidade Federal de Goiás (UFG), as amostras foram submetidas a exames físico-químicos. Após a observação dos resultados ao exame físicoquímico, procedeu-se à semeadura das amostras para bacteriologia. Do sedimento de todas as amostras foram feitos esfregaços em lâmina, que foram submetidos a exame de imunofluorescência indireta (IFI) para Actinobaculum suis.

As características físicas examinadas foram cor, odor e presença de turbidez. Quanto à cor da urina, as amostras foram classificadas visualmente em incolor, amarelo claro e amarelo escuro. Quanto ao odor, as amostras foram classificadas em odor característico da espécie e odor amoniacal. Com relação à turbidez, as amostras foram classificadas em límpida, turva e turva com grumos (WENDT, 1992; WENDT et al., 1993; SOBESTIANSKY et al., 1995; ALBERTON, 1996).

O exame químico da urina foi realizado utilizando-se tiras reagentes ${ }^{\mathrm{a}}$ determinando-se $\mathrm{pH}$, presença de nitrito, sangue e densidade. Nos casos de prova nitrito com resultado negativo, realizou-se então a segunda prova, adicionando-se à sub-amostra de $5 \mathrm{ml}$, 3 gotas de solução de nitrato de potássio $\left(\mathrm{KNO}_{3}\right)$ a $5 \%$. As amostras assim preparadas foram incubadas a $37^{\circ} \mathrm{C}$ durante quatro horas, realizando-se o exame com a tira reagente para verificar a presença de nitrito. Através da leitura, foi possível determinar a ausência ou presença de sangue. A zona reativa para densidade contém um indicador misto que mede valores entre 1,000 e 1,030 (WENTZ, 1976).

\section{Procedimentos bacteriológicos}

No Laboratório de bacteriologia, imediatamente após a chegada das amostras de urina, parte foi inoculada em Caldo Selenito Cistina e outra parte semeada em meio seletivo Ágar Mac Conkey e incubadas a $37^{\circ} \mathrm{C}$ por $18-24$ horas, com o objetivo de isolar e identificar patógenos presentes. As placas de Ágar Mac Conkey foram observadas após 24 horas e três tipos de cada colônia foram transferidas para Ágar triplice açúcar ferro (TSI) que novamente foram incubadas a $37^{\circ} \mathrm{C}$ por mais 24 horas. As amostras que estavam no Caldo Selenito Cistina foram repicadas em Ágar Mac Conkey e incubadas a $37^{\circ} \mathrm{C}$ por 24 horas. Do mesmo modo as colônias crescidas foram transferidas para o TSI e incubadas a $37^{\circ} \mathrm{C}$ por 24 horas. Foram selecionados até três tubos contendo TSI que apresentaram o mesmo tipo de comportamento bacteriano os quais foram submetidos aos seguintes testes bioquímicos, segundo BARON et al. (1980): produção de urease, de indol, prova vermelho de metila, utilização de citrato de Simmons, de fenilalanina desaminase, de glicose, de lactose, de sacarose e de malonato. Quando necessário, foram realizados outros testes como oxidase, $\mathrm{KOH}$ a $3 \%$ e coloração pelo método de Gram.

\section{Identificação de agentes etiológicos - Actinobaculum suis}

A pesquisa de Actinobaculum suis no sedimento urinário foi feita pela imunofluorescência indireta, realizada segundo metodologia descrita por LANGFELDT et al. (1990), WENDT (1992) e WENDT et al. (1993) sendo o antisoro anti - Actinobaculum suis e o conjugado para o exame cedidos pela Escola Superior de Veterinária de Hannover / Alemanha utilizando-se as 
seguintes diluições do anti - soro e do conjugado: 1:150 e de 1:500, respectivamente. Para a preparação do esfregaço, utilizou-se o sedimento da urina. Após homogeneizar a amostra, $5 \mathrm{ml}$ de urina foram centrifugadas a $1500 \mathrm{rpm} / 5$ minutos; com o auxílio da alça de platina fez-se o esfregaço de pequena quantidade de sedimento em lâminas de microscopia que foram secas ao ar e, posteriormente, fixadas sobre chama. As lâminas foram identificadas com o número das fêmeas e mantidas em temperatura ambiente até o momento do exame. Os critérios utilizados para avaliação das lâminas foram os seguintes: negativo para Actinobaculum suis: ausência de bastonetes fluorescentes ou raros bastonetes com fluorescência leve, não característica nas suas bordas; positivo para Actinobaculum suis: presença de bastonetes com forte fluorescência celular ou forte fluorescência nas suas bordas (WENDT et al., 1993; SOBESTIANSKY et al. 1995).

\section{RESULTADOS E DISCUSSÃO}

A presença de infecção urinária foi identificada em todas as granjas envolvidas no estudo, com valores variando de $28,6 \%$ a $75 \%$. Resultado semelhante foi relatado por CARVALHO (1990), que, através do exame de urina colhida antes do abate de 104 porcas descartadas por transtornos reprodutivos, diagnosticou a presença de cistite em $56 \%$ das porcas.

Considerando o número total de amostras de urinas examinadas, verifica-se que houve predominância da cor amarelo escuro $(60 \%)$, de odor característico $(71,4 \%)$, ausência de turbidez $(37,1 \%)$ e ausência de nitrito e sangue $(60 \%$ e $94,3 \%$, respectivamente). Além disto, houve predominância de $\mathrm{pH}$ normal $(71,4 \%)$ e 24 ( 68,6\%) das 35 amostras de urina apresentaram densidade maior que 1,012.

Dentre as $16(16 / 35)$ porcas portadoras de infecção urinária, $8(50 \%)$ das amostras mostraram coloração amarelo escuro, e $6(37,5 \%)$ amarelo claro. Resultados similares foram obtidos por SOBESTIANSKY \& WENDT (1993) que afirmam que a urina das porcas com infecção urinária tende a apresentar coloração amarelo escuro. Já ALBERTON (1996), encontrou, em porcas portadoras de infecção urinária, predominância de coloração amarelo claro $(62,5 \%)$ e correlação da cor da urina com outras variáveis físico-químicas, demonstrando assim que este parâmetro pode ser influenciado por uma série de fatores e, por isso, não deve ser utilizado isoladamente para estimar a presença de infecção urinária em porcas.

Com relação ao odor da urina, ALBERTON (1996) afirma que este exame, apesar de subjetivo, pode dar indicativos da existência de infecção urinária. Pode- se observar 10 amostras $(28,6 \%)$ com odor amoniacal. Destas, 7 (43,8\% ) eram positivas para infecção urinária, concordando com as afirmações de CARR \& WALTON (1990), DEE(1992), SOBESTIANSKY \& WENDT (1993) e ALBERTON (1996). Entretanto COLES (1989) ressalta que o odor amoniacal está presente quando existem, de modo geral, bactérias capazes de transformar nitrato em nitrito, tais como Citrobacter spp., Enterobacter spp., Proteus spp., Morganella morganii, entre outros.

A turbidez da urina ocorre quando há presença de células ou debris tissulares, indicando reação inflamatória, mas pode ser causada pela precipitação de sais na bexiga, principalmente fosfato amorfo (JONES, 1992). No presente estudo, de 35 amostras, $13(37,1 \%)$ foram classificadas como límpidas. Destas, $8(42,1 \%)$ foram negativas para presença de infecção urinária e $5(31,2 \%)$, positivas. Das 12 amostras turvas $(34,3 \%), 7(36,8 \%)$ foram negativas e $5(31,2 \%)$ foram positivas para infecção urinária. Das $10(28,6 \%)$ amostras classificadas como turva com grumos, observou-se $6(37,6 \%)$ positivas para infecção urinária e $4(21,1 \%)$ negativas. Nas 19 amostras negativas, houve predomínio das urinas límpidas $(8,42,1 \%)$, enquanto nas positivas predominaram as urinas turvas com presença de grumos $(6,37,6 \%)$. ALBERTON (1996) observou $83,1 \%$ de urinas turvas, sendo que destas $90,2 \%$ foram positivas para infecção urinária. KANTEC GARCIA-NAVARRO (1996) ressalta que a urina de qualquer espécie animal pode turvar-se, por precipitação dos sais nela eventualmente presentes. Neste contexto, SOBESTIANSKY \& WENDT (1993) recomendam o exame do sedimento que permite identificar a causa da turvação da urina que pode ser a presença de pús, sangue e precipitação de sais minerais.

Com relação ao pH, das 35 amostras de urina examinadas, observou-se que $25(71,4 \%)$ tinham $\mathrm{pH}$ normal que, segundo SOBESTIANSKY et al., (1995) e ALBERTON (1996), pode variar de 5,5 a 6,5. Destas, 12 $(63,1 \%)$ foram consideradas negativas para infecção urinária. Das 10 amostras $(28,6 \%)$ com pH acima de 6,5, $3(18,7 \%)$ foram positivas para infecção urinária. Os resultados observados neste estudo, considerando a presença de infecção urinária, não concordam com a literatura consultada. COLES (1989) descreve que nos casos de infecção urinária espera-se encontrar urinas alcalinas, pois a microbiota localizada nas vias urinárias, transforma uréia em amônia, levando à alcalinização da urina. SOBESTIANSKY \& WENDT (1993) observam que, nos casos de infecção urinária, o pH da urina varia entre 8,0 e 9,0 .

Os valores encontrados para densidade das amostras das urinas analisadas foram enquadrados em 
3 grupos; abaixo de 1,008, entre 1,008 e 1,012 e acima de 1,012. Das 35 amostras analisadas, 7 (20\%) estavam no primeiro grupo, sendo 4 (25\%) positivas para infecção urinária. Quatro amostras foram classificadas no segundo grupo, das quais $3(18,8 \%)$ foram positivas para infecção urinária. Das 24 amostras do último grupo, notou-se $9(56,2 \%)$ positivas para infecção urinária. Existe relação direta entre a restrição do consumo de água em porcas em gestação e a ocorrência de infecção urinária. De acordo com ALBERTON et al. (1996), a densidade da urina tem relação direta com a quantidade de água ingerida pela porca. Assim, quando a quantidade é suficiente, insuficiente ou se encontra em um limite crítico, a densidade da urina é menor que 1,008 , maior que 1,012 e entre 1,008 e 1,012, respectivamente (ALBERTON et al., 1996). Neste estudo observou-se predomínio das urinas com densidades superiores a 1,012 (24,68,6\%).

Exame microbiológico

Constatou-se a presença de bactérias na urina (bacteriúria) em 91,5\% das 35 amostras de urina examinadas. Este resultado é maior do que o obtido por AKKERMANS \& POMPERS (1980) que registraram bacteriúria em $12,5 \%$ de 827 fêmeas suínas provenientes de granjas sem e em 16\% de 615 fêmeas suínas provenientes de granjas com problemas reprodutivos. Da mesma forma, os resultados aqui expostos são superiores à freqüência de $31,7 \%$ de bacteriúria registrada por CARVALHO (1990) em estudo realizado no Brasil envolvendo 104 fêmeas descartadas por problemas reprodutivos. Por outro lado, WENTZ (1987) registrou bacteriúria em $97,4 \%$ de 82 fêmeas descartadas por problemas reprodutivos e outras razões, valores semelhantes aos aqui descritos.

A bactéria isolada com maior freqüência foi Escherichia coli, tanto em cultura pura (45,7\%) como em cultura mista (11,4\%). Segundo SOBESTIANSKY \& WENDT (1993), a microbiota envolvida na infecção urinária caracteriza-se por ser essencialmente fecal com predominância de Escherichia coli, o que concorda com os resultados obtidos neste trabalho, bem como com aqueles descritos por BERNER (1978), MADEC \& DAVID (1983), MADEC (1984), NAKAJIMA (1984), WENTZ(1987)ePERESTRELO\&PERESTRELO(1988). Com relação ao isolamento de Morganella morganii; Pseudomonas spp. e Citrobacter spp., não foi encontrada referência na literatura consultada.

\section{de Actinobaculum suis}

Imunofluorescência indireta para presença

Das 35 fêmeas examinadas, $11(31,4 \%)$ albergavam Actinobaculum suis no trato urinário, sendo que $4(25 \%)$ amostras foram simultaneamente positivas para infecção urinária e Actinobaculum suis e 7
(36,9\%) negativas para infecção urinária porém positivas para presença de Actinobaculum suis, o que de certa forma reforça as afirmações de LANGFELDT et al. (1990), que consideram a imunofluorescência indireta um teste pouco seguro e confiável e de baixa sensibilidade. No Brasil, em estudos envolvendo fêmeas de descarte, não tem sido incluída na metodologia a identificação do Actinobaculum suis por imunofluorescência indireta (IFI) nem pelo cultivo bacteriológico para o isolamento (WENTZ, 1987; REIS et al., 1992; CARVALHO, 1990). Desta forma, não foram encontrados subsídios na literatura consultada para comparar e discutir os resultados obtidos.

Por outro lado, quando se compara os resultados deste estudo com aqueles realizados para estudar a prevalência deste agente no Brasil, constatase porcentagens mais elevadas em relação às registradas por SOBESTIANSKY \& DALLA COSTA (1995), VAZ et al., (1995) e ALBERTON (1996), cujas taxas de prevalência foram $12 \%$; $17 \%$ e $20,63 \%$ respectivamente. A presença simultânea de infecção urinária e Actinobaculum suis também foi constatada por VESPER (1991) e ALBERTON (1996) em trabalhos realizados na Alemanha e Brasil; porém em taxa menor que os $25 \%$ descritos no presente relato. Deve-se ressaltar, no entanto, que VESPER (1991) analisou 637 amostras de urina, das quais $4,6 \%$ apresentavam positividade para infecção urinária e Actinobaculum suis, assim como ALBERTON (1996) utilizou amostras de 1585 fêmeas, notando 3,6\% de amostras com esta característica.

Nos dados obtidos, verifica-se que o número de fêmeas portadoras de Actinobaculum suis sem infecção urinária $(36,9 \%)$ é maior que o número de fêmeas com presença simultânea de infecção urinária e de Actinobaculum suis (25\%). Esta proporção é semelhante àquela obtida por ALBERTON (1996) e ambos estão de acordo com a sugestão de VESPER (1991) e WENDT (1992), de que a ocorrência de Actinobaculum suis na fêmea suína é mais freqüente que o comumente suposto, que provavelmente a fêmea suína albergue Actinobaculum suis no trato urinário e que, ao ser submetida a determinados fatores de risco, a infecção se estabelece com diferentes graus de severidade.

\section{CONCLUSÕES}

Nas condições desse experimento, pode-se concluir que: 1 . Observou-se a presença de infecção urinária em todas as granjas envolvidas neste estudo. 2. Com relação ao exame físico-químico pode-se afirmar que, nas fêmeas positivas para infecção urinária, observou-se predomínio de: urinas de coloração amarelo escuro; urinas com odor amoniacal; urinas turvas 
com presença de grumos e valores de $\mathrm{pH}$ considerados normais $(5,5-6,5)$, independente da presença de infecção urinária. 3. A bactéria isolada com maior freqüência foi a Escherichia coli. 4. Actinobaculum suis está presente em urinas normais.

\section{AGRADECIMENTOS}

Agradecemos aos Prof. Drs. Günter Amstberg e Michael Wendt Escola Superior de Veterinária de Hannover Alemanha pela cedência do antisoro anti- Actinobaculum suis e do conjugado para realização dos exames de imunofluorescência indireta.

\section{FONTEDEAQUISIÇÃO}

Científicos Ltda.

${ }^{a}$ Self - Stikâ - Reagent Strips - Protec Produtos

\section{REFERÊNCIASBIBLIOGRÁFICAS}

AKKERMANS, J.P.W.M.; POMPERS, W. The significance of a bacteriuria with reference to disturbances in fertility. In: INTERNATIONAL PIG VETERINARY SOCIETY CONGRESS, 6, 1980, Copenhagen. Proceedings... Copenhagen : IPVS, 1980. p.44.

ALBERTON, G.C. Prevalência e correlação entre infecção urinária, Actinomyces suis e alguns parâmetros físicos e químicos da urina em porcas gestantes. 1996. 46fp. Dissertação (Mestrado em Ciência Veterinárias), Universidade Federal do Paraná.

ALBERTON, G.C. et al. Valores da densidade da urina de porcas com e sem infecção urinária. In: CONGRESSO PANAMERICANO DE CIÊNCIAS VETERINÁRIAS, 15, 1996, Campo Grande. Abstracts... Campo Grande : SBMV, 1996. p. 294.

BARON E.J.O.; PETERSON L.R.; FINEGOLD S.M. Diagnostic Microbiology. 9.ed. Missouri : Mosby, 1980. 958p.

BERNER, H. Die Harnwegsinfektionen beim Schwein. 1978. 427f. Tese (Livre Docência) - Tierärztliche Hochschule München.

CARR, J.; WALTON, J.R. Investigations of the pathogenic properties of Eubacterium (Corynebacterium) suis. In: INTERNATIONAL PIG VETERINARY SOCIETY CONGRESS, 11, 1990, Lausanne. Proceedings... S.1. : IPVS, 1990. p.178.

CARVALHO, L.F. de O.S. Investigação clínica, anatomopatológica e citogenética de fêmeas suínas com transtornos reprodutivos. 1990. 95f. Tese (Doutorado em Medicina Veterinária) - Curso de Pós-graduação em Medicina Veterinária, Faculdade de Medicina Veterinária e Zootecnia UNESP.

COLES, E.H. Prueblas de funcionamento renal. In: COLES, E.H. Diagnóstico y Patologia en Veterinária. Mexico : Interamericana, 1989. p.175 - 206.

DEE, S.A. Porcine urogenital disease. Veterinary Clinics of North America: Food Animal Practice, Morris, v. 8, n.3, p.641 - 660, 1992.
JONES,J.E.T. et al. Diseases of swine. 7.ed. London : Wolfe, 1992. p.217-222.

KANTEK GARCIA - NAVARRO, C. E. Manual de urinálise. São Paulo : Varela, 1996. 96p.

LANGFELDT, N.; WENDT, M.; ANTSBERG, G. Vergleichende Untersuchungen zum Nachweis von Corynebacterium suis Infektion beim Schwein mit Hilfe der indirekten Imunofluoreszenz und der Kultur. Berliner Munchner Tierärztliche Wochenschrift, v.103, p.273-276, 1990.

MADEC, F. Urinary disorders in intensive herds. Pig News and Information, v.5, n.2, p.89-93, 1984.

MADEC, F.; DAVID, F. Les troubles urinaires des troupeau de truies: diagnostic, incidence et circonstances d'apparition. Journées Recherche Porcine, v.15. p.431-446, 1983.

NAKAJIMA, M. Infecções urinárias em porcas do Estado de Minas Gerais. 1984. 43f. Dissertação (Mestrado em Medicina Veterinária) - Curso de Pós-graduação em Medicina Veterinária, Universidade Federal de Minas Gerais.

PERESTRELO, R.; PERESTRELO, H. Transtornos urinários en las explotaciones intensivas de cerdos en Portugal. Anaporc, v.68, p.62-71, 1988.

PETERSEN, B. Harnuntersuchugen bei Sauen. Ein Beitrag zur vorsorge von puerperalen Infektionen und Fruchtbarkeits storungen. 1980. 92f. Tese (Doutorado em Medicina Veterinária) - Curso de Pós-graduação em Medicina Veterinária, Lanwirtschaftliche Fakultät.

REIS, R. et al. Infecções urinárias em porcas. Arquivo Brasileiro de Medicina Veterinária e Zootecnia. v. 44, n. 5, p. 363-376, 1992.

SOBESTIANSKY, J.; DALLA COSTA, O. A. Infecção urinária na fêmea em produção: resultados preliminares de estudo de prevalência de Eubacterium suis. In: CONGRESSO BRASILEIRO DE VETERINÁRIOS ESPECIALISTAS EM SUÍNOS, 7., 1995, Blumenau, SC. Anais... Blumenau : ABRAVES, 1995. p.118.

SOBESTIANSKY, J. et al. Infecção urinária na fêmea suína em produção: Ocorrência em granjas com queda da eficiência reprodutiva. In: CONGRESSO BRASILEIRO DE VETERINÁRIOS ESPECIALISTAS EM SUÍNOS, 7., 1995, Blumenau, SC. Anais... Blumenau : ABRAVES, 1995. p.68.

SOBESTIANSKY, J.; WENDT, M. Infecção urinária na fêmea suína: epidemiologia, sintomatologia, diagnóstico e controle. In: CONGRESSO BRASILEIRO DE VETERINÁRIOS ESPECIALISTAS EM SUÍNOS, 6., 1993, Goiânia, GO. Anais... Goiânia: ABRAVES, 1993. p.51 - 63 .

VAZ, E.R. et al. Prevalência do Eubacterium suis no Planalto Catarinense. In: CONGRESSO BRASILEIRO DE VETERINÁRIOS ESPECIALISTAS EM SUÍNOS, 7., 1995, Blumenau, SC. Anais... Blumenau : ABRAVES, 1995. p.119.

VESPER, C. Untersuchungen zum Vorkommen von Harnwegsinfektionem in Zuchtsauenbestanden unter besonderer Berücksichtigung von Eubacterium suis Infektion. 1991. $108 \mathrm{f}$. 
Tese (Doutorado em Medicina Veterinária) - Curso de Pós-graduação em Medicina Veterinária, Tierärtzliche Hochschule Hannover.

WENDT, M. Untersuchungen zur Diagnostik und zur Charakterisierung von Harnwegsinfektionen der Sau unter besonderer Berücksichtigung von Eubacterium suis. 1992. 242f. Tese (Livre Docência) - Tierärztliche Hochschule Hannover.

WENDT, M.; SOBESTIANSKY, J.; AMTSBERG, G. Infecções urinárias em suínos: identificação de Eubacterium suis por Imunofluorescência directa. Revista Portuguesa de Ciências
Veterinárias, Lisboa, v.88, n.508, p.176-180, 1993.

WENTZ, I. Significado clínico das infecções urinárias nas falhas de fertilidade. Concórdia : EMBRAPA - Centro Nacional de Pesquisa de Suínos e Aves, 1987. (EMBRAPA.Programa Nacional de Pesquisa Projeto n. $\left.{ }^{\circ} 01184012 / 1\right)$.

WENTZ, I. Untersuchungen des Harns und Geschlechsapparates bei Sauen nac Schnittenbindungen mit Berücksichtigung klinisceher und baketriologischer Aspekte. 1976. 56f. Tese (Doutorado em Medicina Veterinária) - Curso de Pós-graduação em Medicina Veterinária, Tierärtzliche Hochschule Hannover. 